\title{
Treatment of osteonecrosis of the femoral head by core decompression and implantation of fully functional ex vivo-expanded bone marrow-derived mesenchymal stem cells: a proof-of-concept study
}

This article was published in the following Dove Medical Press journal: Stem Cells and Cloning:Advances and Applications

\author{
Rodrigo Mardones' \\ Daniel Camacho',2 \\ Francisco Monsalvo' \\ Nicolás Zulch' \\ Claudio Jofre ${ }^{3}$ \\ José J Minguell ${ }^{3}$ \\ 'Department of Orthopedics, \\ Clínica Las Condes, Santiago, Chile; \\ ${ }^{2}$ Department of Orthopedics, \\ Instituto Traumatológico, Santiago, \\ Chile; ${ }^{3}$ Centro de Terapia \\ Regenerativa Celular, Clínica Las \\ Condes, Santiago, Chile
}

\begin{abstract}
Background: Based on several attributes involved in bone formation, bone marrow-resident mesenchymal stem cells (MSCs) have been employed in the treatment of patients suffering from femoral head osteonecrosis. Due to the low content of MSCs in the bone marrow, ex vivo expansion procedures are utilized to increase the cell number. Customarily, before administration of the resulting expanded cell product MSCs to the patient, its cellular identity is usually evaluated according to a set of "minimal phenotypic" markers, which are not modified by ex vivo processing. However, MSC functional ("reparative") markers, which are severely impaired along the ex vivo expansion routine, are usually not assessed.
\end{abstract}

Patients and methods: In this proof-of-concept study, a cohort of five avascular osteonecrosis patients received an instillation of ex vivo-expanded autologous MSCs, manufactured under controlled conditions, with an aim to protect their functional ("reparative") capacity.

Results and conclusion: Outcomes of this study confirmed the safety and effectiveness of the MSC-based therapy used. After a follow-up period (19-54 months), in all patients, the hip function was significantly improved and pain intensity markedly reduced. As a corollary, no patient required hip arthroplasty.

Keywords: avascular necrosis, femoral head, osteonecrosis, mesenchymal stem cell-based therapy

\section{Introduction}

Avascular necrosis (AVN), also called osteonecrosis, aseptic necrosis or ischemic bone necrosis, is a condition that occurs when blood supply to a bone is interrupted and/or reduced. Therefore, the involved bone might collapse and frequently progress to osteoarthritis. In the early stages of the disease, most treatments are focused on preventing further bone collapse. Among them, nonsteroidal anti-inflammatory drugs and/or other medications are used with an aim to relieve pain and inflammation associated with AVN. In turn, when the disease is fairly advanced, treatment options include total hip arthroscopy (THA) and femoral head core decompression. Given that AVN typically affects young patients, the above-indicated methods do not represent outstanding curative options. ${ }^{1-4}$

Bone regeneration, ${ }^{5,6}$ a rather complex physiological process, involves the participation of several componentsand mesenchymal stem cells (MSCs) are one among them. These have the potential to differentiate into bone-forming cells as well as to
Correspondence: José J Minguell

Centro de Terapia Regenerativa

Celular, Clínica Las Condes, Av. Las

Condes I I283, Torre B-303, CP 7590992,

Santiago, Chile

Tel +56995017675

Email jose.minguell@bioscell.cl 
produce specific signaling molecules (growth factors, cytokines, others) and extracellular matrix molecules..$^{7-10}$ As a result, several studies have been performed to assess in AVN patients the clinical effectiveness elicited by the instillation of diverse bone marrow products containing MSCs. The latter include bone marrow aspirates, ${ }^{11,12}$ bone marrow-derived mononuclear cell fraction ${ }^{13,14}$ and/or bone-marrow-derived ex vivo-expanded autologous MSCs. ${ }^{15-17}$

In almost all reported clinical studies employing MSCs as the "reparative cell product", the standard criteria for MSC characterization include the assessment of a "minimal set" of phenotypical attributes, including morphology, in vitro differentiation and expression/no expression of a set of surface molecules. ${ }^{18}$ However, the latter in any case validates MSC functional ("reparative") status, which is modified alongside ex vivo processing, ${ }^{19-21}$ as well as by patient conditions at inclusion, comprising age, gender, comorbidities and/or concomitant medication. ${ }^{22-28}$

Consequently, the safety and effective use of an ex vivomanipulated MSC product is associated with several factors. Among them are the following factors: 1) the assurance that its functional "reparative" attributes are intact and impinged neither by patient conditions nor by ex vivo manipulations and 2) the implementation of procedural maneuvers assuring the proper delivery as well as the permanence (homing) of the cell product in the damaged zone.

Based on the above remarks, in this proof-of-concept study, a cohort of five AVN patients received an instillation of ex vivo-manipulated autologous bone marrowderived MSCs manufactured under conditions proficient to protect and sustain their phenotypic and functional characteristics..$^{29-32}$

The above comprises an invitation to pay attention to a group of relevant issues involved in the formulation of an MSC-based therapeutic approach. Among them are the following: 1) the preparation by means of ex vivo expansion procedures of an optimum number of fully functional reparative MSCs; 2) the feasibility to perform a core decompression procedure aimed to reduce pressure, increase blood flow and slow down bone and/or joint damage $\mathrm{e}^{14,16}$ and 3) an attempt to prolong the permanence (homing?) of the cell product in the osteonecrotic area, by depositing a plug immediately after cell instillation. ${ }^{13}$

\section{Patients and methods}

\section{Patient population}

Five patients with diagnosis of AVN of the femoral head, which met the following criteria, were included in this proof-of-concept study: 1) AVN at stage 2 or 3 of the Ficat classification system ${ }^{2}$ and 2$)<50 \%$ of the articular area compromised. The clinical characteristics of the study population are presented in Table 1. An X-ray as well as a magnetic resonance imaging (MRI) preoperative image (patient 2) are shown in Figure 2.

\section{Preparation and characterization of the ex vivo-expanded autologous bone marrow-derived cell product}

All study patients had a bone marrow aspiration, and the samples were sent to the adjoining Good Manufacturing practices facility for the isolation and ex vivo expansion of autologous bone marrow-resident MSCs. ${ }^{33,34}$

At the end of each expansion passage, cell aliquots were taken for the assessment of 1) cell number, morphology and viability; 2) "minimal phenotypical markers criteria"18 and 3) functional markers, including fast forward-scattered (FFS) light and cumulative population doubling (CPD), as predictive indicators of MSC-replicative senescence. ${ }^{19-21}$

\section{Instillation of ex vivo-expanded autologous MSCs in patients}

In this proof-of-evidence study, all five AVN patients received the instillation of a unique dose $\left(40 \times 10^{6}\right)$ of ex vivo-expanded autologous bone marrow-derived MSCs into the necrotic zone and through the canal of a preceding core decompression process. In an attempt to further prolong the permanence (homing) of MSCs in the bone-damaged area,

Table I Clinical characteristics of the study population

\begin{tabular}{|l|l|l|l|l|l|}
\hline Patient ID & Age (years) & Gender & AVN feature: side & Ficat class & Comorbidities \\
\hline$\# 1$ & 23 & Male & Left & 3 & No \\
\hline$\# 2$ & 44 & Female & Left & 2 & Lupus erythematosus \\
\hline$\# 3$ & Male & Right & 2 & Hypertension, hypothyroidism \\
\hline$\# 4$ & 59 & Male & Right & 2 & Insulin resistance \\
\hline$\# 5$ & 43 & Male & Left & 2 & No \\
\hline
\end{tabular}

Abbreviation: AVN, avascular necrosis. 
a hydroxyapatite or a calcium phosphate plug ${ }^{35,36}$ was placed immediately after cell instillation (Figure 1).

\section{Ethics statement}

All procedures performed in this study have been carried out according to the ethical guidelines outlined by the Ethics Committee (Institutional Review Board) of Clinica Las Condes, Santiago, Chile (July 27, 2016). Clinica Las Condes is a medical center affiliated with John Hopkins Medicine International and accredited by the Joint Commission International (http://www.jointcommissioninternational.org). In addition, written informed consent was provided by the patients, in accordance with the Declaration of Helsinki.

\section{Results \\ Characterization of the ex vivo-expanded autologous bone marrow-derived MSC products}

The ex vivo-expanded autologous MSC product, obtained at the end of each expansion cycle, was assessed for 1) cell number, morphology and viability; 2) expression of a set of "minimal phenotypical markers"18 and 3) flow cytometry analysis to calculate FFS and CPD values. The latter are usu- ally considered predictive indicators of cellular functionality and thus replicative senescence. ${ }^{19-21,29,30}$ The results of these studies are shown in Table 2.

\section{Patients' clinical outcomes after the infusion of ex vivo-expanded autologous bone marrow-derived MSCs}

As shown in Table 3, at different times after instillation of the ex vivo-expanded autologous cell product, all five patients exhibited an improvement in the modified Harris hip score, from a preoperative mean value of 73.6 (range 47-95) to a postoperative mean value of 98.2 (range 95-100). In turn, the visual analog scale values improved from a preoperative mean value of 4.6 to a postoperative mean value of 0.4 . Remarkably, the above results matched with a sustained change observed in the X-ray and MRI images of the pelvis of patient \#3, after an extended follow-up period (Figure 2). The above findings are representative of similar results observed in patients \#1, 2, 4 and 5 (not shown).

The above data reinforce the notion that the instillation of a "minimally manipulated" ex vivo-expanded autologous bone marrow-derived MSC product ${ }^{30,31}$ emerges as an outstanding therapeutic option for AVN patients.
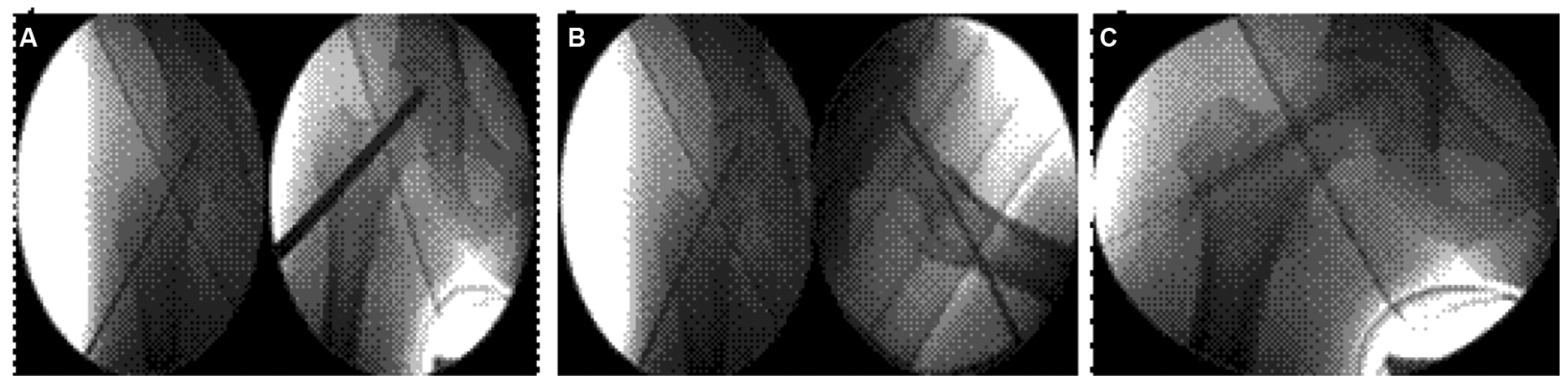

Figure I Intraoperative radioscopic views of (A) passing of the $10 \mathrm{~mm}$ cannulated drill to the center of the necrotic area in both planes (AP and axial view), (B) the infusion of ex vivo-expanded autologous MSCs into the necrotic area and (C) the subsequent syringe filling of the drilling canal. In all cases, the guide wire was stopped at the subchondral bone of the necrotic area.

Abbreviation: AP, anteroposterior.

Table 2 Assessment of phenotypical and functional attributes of ex vivo-expanded bone marrow-derived MSCs

\begin{tabular}{|c|c|c|c|c|}
\hline \multirow[t]{2}{*}{ Patient ID } & \multirow[t]{2}{*}{ Expansion cycles ${ }^{a}$} & \multirow{2}{*}{$\begin{array}{l}\text { Fulfillment of "minimal } \\
\text { phenotypical" markers }\end{array}$} & \multicolumn{2}{|c|}{ Functional markers $^{c}$} \\
\hline & & & CPD & FFS \\
\hline$\# 1$ & 2 & Yes & $1.2 / 1.2$ & $92 / 94$ \\
\hline$\# 2$ & 3 & Yes & $1.5 / 1.5$ & 93/95 \\
\hline$\# 3$ & 2 & Yes & $1.8 / 1.7$ & $92 / 95$ \\
\hline$\# 4$ & 3 & Yes & $1.6 / 1.5$ & 93/95 \\
\hline$\# 5$ & 2 & Yes & $1.4 / 1.4$ & $92 / 94$ \\
\hline
\end{tabular}

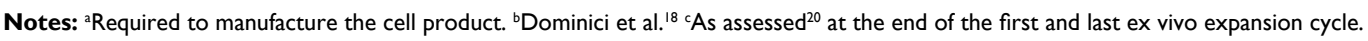
Abbreviations: CPD, cumulative population doubling; FFS, fast forward scatter. 


\section{Discussion}

As indicated in the "Introduction" section, in the last 10 years, several clinical studies have been initiated to treat AVN patients by the instillation of different types of "reparative

Table 3 Patients' clinical outcome after instillation of the ex vivoexpanded autologous MSC-based product

\begin{tabular}{|l|l|l|l|l|l|}
\hline Patient & \multirow{2}{*}{$\begin{array}{l}\text { Time elapsed } \\
\text { IDom cell } \\
\text { infusion } \\
\text { (months) }\end{array}$} & \multicolumn{2}{l|}{$\begin{array}{l}\text { Modified Harris } \\
\text { hip score }\end{array}$} & \multicolumn{2}{l|}{$\begin{array}{l}\text { Visual analog } \\
\text { scale }\end{array}$} \\
\cline { 2 - 6 } & Before & After & Before & After \\
\hline$\# I$ & 50 & 90 & 100 & 6 & 0 \\
\hline$\# 2$ & 36 & 95 & 100 & 3 & 0 \\
\hline$\# 3$ & 37 & 71 & 96 & 5 & 0 \\
\hline$\# 4$ & 31 & 65 & 100 & 4 & 1 \\
\hline$\# 5$ & 15 & 47 & 95 & 5 & 1 \\
\hline
\end{tabular}

cell products" containing MSCs. The clinical use of MSCs is reinforced by a set of attractive cellular and molecular attributes, including among many others a differentiation potential into bone-forming cells, as well as competence to produce and release a variety of growth factors and extracellular matrix components. ${ }^{5,7,9,30}$

Despite the abundance of tissue sources of MSCs, in a vast majority of clinical studies, patients have received instillation of diverse bone marrow-derived MSCs products. Some of them are as follows: 1) a bone marrow suspension, 2) a bone marrow-derived mononuclear cell fraction and 3) ex vivo-expanded bone marrow-derived MSCs. In the first two cases, despite the absolute number of MSCs obtained being extremely low, their cellular and functional attributes are intact. ${ }^{7,8,30,31}$ Consequently, ex vivo expansion procedures
A

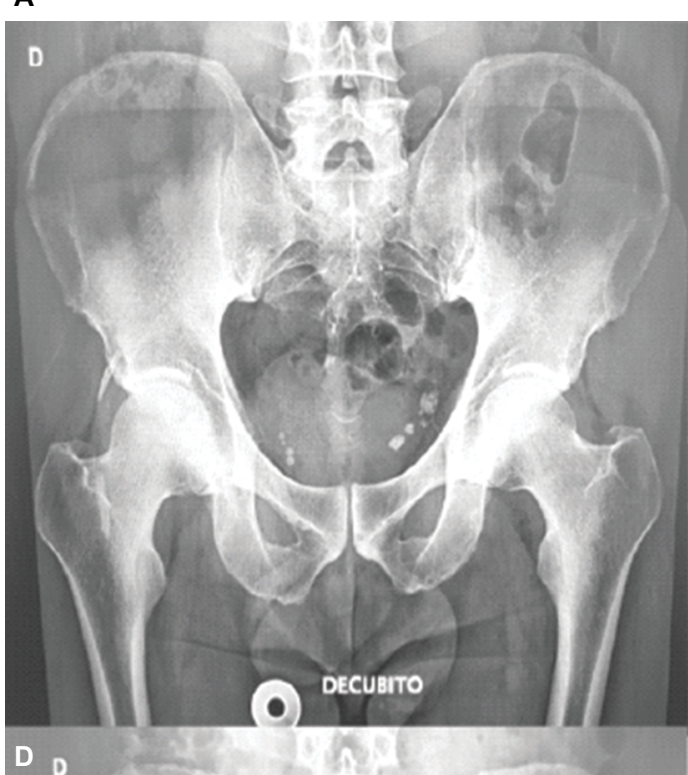

B
C

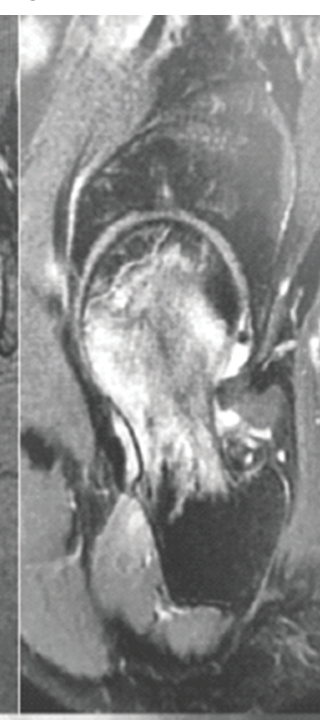

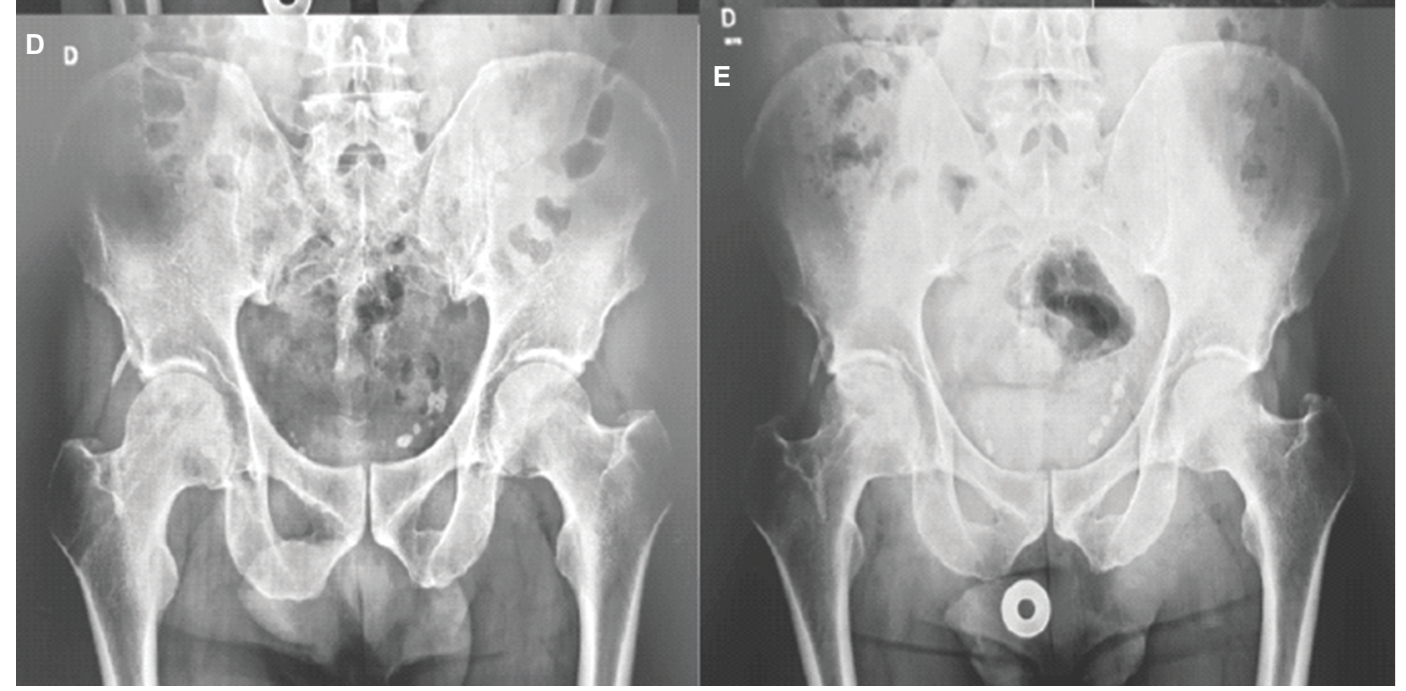

Figure 2 X-ray and/or MRI images of the pelvis of an AVN patient (\#3) at inclusion in the study (A, B, C), immediately after the cell infusion (D) and after a 3-year followup period $(\mathbf{E})$.

Abbreviation: AVN, avascular necrosis; MRI, magnetic resonance imaging. 
have been developed to increase the cell number, thus allowing the instillation of an appropriate number of ex vivo-expanded autologous MSCs to patients. The resulting expanded MSCs are usually assessed for the expression of conventional phenotypic markers, ${ }^{18}$ but not for functional (reparative) markers, which are known to be affected by ex vivo expansion. ${ }^{19,20,30-32}$

In this proof-of-evidence study, a cohort of five AVN patients received the infusion of a unique dose of ex vivoexpanded autologous bone marrow-derived MSCs into the necrotic zone and through the canal of a preceding core decompression process. ${ }^{14,16}$ The "reparative cell product" was manufactured under well-controlled conditions (less than three expansion cycles) which, as seen in Table 2, sustain and warrant the full expression of "minimal phenotypic lineageassociated" markers, ${ }^{18}$ as well as of CPD and FFS values, two predictive indicators of senescent events. ${ }^{11,19}$

In addition to the above-mentioned provisions and in an attempt to further prolong the permanence (homing) of instilled cells in the proximity of the bone damaged region, a hemostatic matrix and/or a calcium phosphate cement ${ }^{35,36}$ was instilled nearby the damaged area.

We presume that the procedural provisions taken along this study as well as others ${ }^{37-40}$ emerged as important contributors to the successful clinical outcome that was observed in all five study patients (Table 3). ${ }^{14-16}$

Beyond the appealing clinical outcomes of this study, it is interesting to mention that before the setting up of the Stem Cell Laboratory, the conventional therapy for AVN patients in use at this institution comprised femoral core decompression followed by the infusion of a bone marrowderived mononuclear cell grafting. ${ }^{14-16}$ Results indicated that $\geq 80 \%$ of patients treated with the cell grafting had a treatment failure requiring THA (R Mardones et al, 2018; unpublished data).

\section{Disclosure}

The authors report no conflicts of interest in this work.

\section{References}

1. Lavernia CJ, Sierra RJ, Grieco FR. Osteonecrosis of the femoral head. J Am Acad Orthop Surg. 1999;7(4):250-261.

2. Aldridge JM, Urbaniak JR. Avascular necrosis of the femoral head: etiology, pathophysiology, classification, and current treatment guidelines. Am J Orthop (Belle Mead NJ). 2004;33(7):327-332.

3. Filardo G, Kon E, Pereira Ruiz MT, et al. Platelet-rich plasma intraarticular injections for cartilage degeneration and osteoarthritis: singleversus double-spinning approach. Knee Surg Sports Traumatol Arthrosc. 2012;20(10):2082-2091

4. Samy AM. Management of osteonecrosis of the femoral head: a novel technique. Indian J Orthop. 2016;50(4):359-365.

5. Dimitriou R, Jones E, Mcgonagle D, Giannoudis PV. Bone regeneration: current concepts and future directions. BMC Med. 2011;9:66.
6. Kane R, Ma1 PX. Mimicking the nanostructure of bone matrix to regenerate bone. Mater Today (Kidlington). 2013;16(11):418-423.

7. Conget PA, Minguell JJ. Phenotypical and functional properties of human bone marrow mesenchymal progenitor cells. J Cell Physiol. 1999;181(1):67-73.

8. Kristjánsson B, Honsawek S. Current perspectives in mesenchymal stem cell therapies for osteoarthritis. Stem Cells Int. 2014;2014:1-13.

9. Hayrapetyan A, Jansen JA, van den Beucken JJ. Signaling pathways involved in osteogenesis and their application for bone regenerative medicine. Tissue Eng Part B Rev. 2015;21(1):75-87.

10. Florencio-Silva R, Sasso GR, Sasso-Cerri E, Simões MJ, Cerri PS. Biology of bone tissue: structure, function, and factors that influence bone cells. Biomed Res Int. 2015;2015:1-17.

11. Hernigou P, Trousselier M, Roubineau F, et al. Stem cell therapy for the treatment of hip osteonecrosis: a 30-year review of progress. Clin Orthop Surg. 2016;8(1):1-8.

12. Gangji V, de Maertelaer V, Hauzeur JP. Autologous bone marrow cell implantation in the treatment of non-traumatic osteonecrosis of the femoral head: five year follow-up of a prospective controlled study. Bone. 2011;49(5):1005-1009.

13. Yamasaki T, Yasunaga Y, Ishikawa M, Hamaki T, Ochi M. Bone-marrowderived mononuclear cells with a porous hydroxyapatite scaffold for the treatment of osteonecrosis of the femoral head: a preliminary study. $J$ Bone Joint Surg Br. 2010;92(3):337-341.

14. Pepke W, Kasten P, Beckmann NA, Janicki P, Egermann M. Core decompression and autologous bone marrow concentrate for treatment of femoral head osteonecrosis: a randomized prospective study. Orthop Rev. 2016;8(1):6162.

15. Zhao D, Cui D, Wang B, et al. Treatment of early stage osteonecrosis of the femoral head with autologous implantation of bone marrow-derived and cultured mesenchymal stem cells. Bone. 2012;50(1):325-330.

16. Li X, Xu X, Wu W. Comparison of bone marrow mesenchymal stem cells and core decompression in treatment of osteonecrosis of the femoral head: a meta-analysis. Int J Clin Exp Pathol. 2014;7(8):5024-5030.

17. Freitag J, Bates D, Boyd R. Mesenchymal stem cell therapy in the treatment of osteoarthritis. BMC Musculoskelet Disord. 2016;17(1):230.

18. Dominici M, Le Blanc K, Mueller I, et al. Minimal criteria for defining multipotent mesenchymal stromal cells. The International Society for Cellular Therapy position statement. Cytotherapy. 2006;8(4): 315-317.

19. Madeira A, da Silva CL, dos Santos F, Camafeita E, Cabral JM, SáCorreia I. Human mesenchymal stem cell expression program upon extended ex-vivo cultivation, as revealed by 2-DE-based quantitative proteomics. PLoS One. 2012;7(8):e43523.

20. Turinetto V, Vitale E, Giachino C. Senescence in human mesenchymal stem cells: functional changes and implications in stem cell-based therapy. Int J Mol Sci. 2016;17(7):1164.

21. Kobolak J, Dinnyes A, Memic A, Khademhosseini A, Mobasheri A. Mesenchymal stem cells: identification, phenotypic characterization, biological properties and potential for regenerative medicine through biomaterial micro-engineering of their niche. Methods. 2016;99: 62-68.

22. Siegel G, Kluba T, Hermanutz-Klein U, Bieback K, Northoff H, Schäfer R. Phenotype, donor age and gender affect function of human bone marrow-derived mesenchymal stromal cells. BMC Med. 2013;11:146.

23. Schimke MM, Marozin S, Lepperdinger G. Patient-specific age: the other side of the coin in advanced mesenchymal stem cell therapy. Front Physiol. 2015;6:362.

24. Lee OK, Ko YC, Kuo TK, et al. Fluvastatin and lovastatin but not pravastatin induce neuroglial differentiation in human mesenchymal stem cells. J Cell Biochem. 2004;93(5):917-928.

25. Deng L, Hu S, Baydoun AR, Chen J, Chen X, Cong X. Aspirin induces apoptosis in mesenchymal stem cells requiring Wnt/beta-catenin pathway. Cell Prolif. 2009;42(6):721-730.

26. Almaawi A, Wang HT, Ciobanu O, et al. Effect of acetaminophen and nonsteroidal anti-inflammatory drugs on gene expression of mesenchymal stem cells. Tissue Eng Part A. 2013;19(7-8):1039-1046. 
27. Verdi J, Mortazavi-Tabatabaei SA, Sharif S, Verdi H, Shoae-Hassani A. Citalopram increases the differentiation efficacy of bone marrow mesenchymal stem cells into neuronal-like cells. Neural Regen Res. 2014;9(8):845-850.

28. Veyrat-Masson R, Boiret-Dupré N, Rapatel C, et al. Mesenchymal content of fresh bone marrow: a proposed quality control method for cell therapy. Br J Haematol. 2007;139(2):312-320.

29. Wagner W, Horn P, Castoldi M, et al. Replicative senescence of mesenchymal stem cells: a continuous and organized process. PLoS One. 2008;3(5):e2213.

30. Minguell JJ, Allers C, Lasala GP. Mesenchymal stem cells and the treatment of conditions and diseases: the less glittering side of a conspicuous stem cell for basic research. Stem Cells Dev. 2013;22(2):193-203.

31. Ikebe C, Suzuki K. Mesenchymal stem cells for regenerative therapy: optimization of cell preparation protocols. Biomed Res Int. 2014;2014:1-11.

32. Torre ML, Lucarelli E, Guidi S, et al. Ex vivo expanded mesenchymal stromal cell minimal quality requirements for clinical application. Stem Cells Dev. 2015;24(6):677-685.

33. Smith AJ, O'Rorke RD, Kale A, et al. Rapid cell separation with minimal manipulation for autologous cell therapies. Sci Rep. 2017;7:41872.

34. Mardones R, Jofré CM, Tobar L, Minguell JJ. Mesenchymal stem cell therapy in the treatment of hip osteoarthritis. J Hip Preserv Surg. 2017;4(2):159-163.
35. Elmengaard B, Bechtold JE, Chen X, Søballe K. Fixation of hydroxyapatite-coated revision implants is improved by the surgical technique of cracking the sclerotic bone rim. J Orthop Res. 2009;27(8):996-1001.

36. Ng VY, Granger JF, Ellis TJ. Calcium phosphate cement to prevent collapse in avascular necrosis of the femoral head. Med Hypotheses. 2010;74(4):725-726.

37. Misra K, Sabaawy HE. Minimally manipulated autologous adherent bone marrow cells (ABMCs): a promising cell therapy of spinal cord injury. Neural Regen Res. 2015;10(7):1058-1060.

38. Piuzzi NS, Chahla J, Jiandong H, et al. Analysis of cell therapies used in clinical trials for the treatment of osteonecrosis of the femoral head: a systematic review of the literature. J Arthroplasty. 2017;32(8): 2612-2618.

39. Mazzanti B, Lorenzi B, Borghini A, et al. Local injection of bone marrow progenitor cells for the treatment of anal sphincter injury: in-vitro expanded versus minimally-manipulated cells. Stem Cell Res Ther. 2016;7(1):85.

40. Nitkin CR, Bonfield TL. Concise review: mesenchymal stem cell therapy for pediatric disease: perspectives on success and potential improvements. Stem Cells Transl Med. 2017;6(2):539-565.
Stem Cells and Cloning: Advances and Applications

\section{Publish your work in this journal}

Stem Cells and Cloning: Advances and Applications is an international, peer-reviewed, open access journal. Areas of interest in stem cell research include: Embryonic cell stems; Adult stem cells; Blastocysts; Cordblood stem cells; Stem cell transformation and culture; Therapeutic cloning; Umbilical cord blood and bone marrow cells; Laboratory,

\section{Dovepress}

animal and human therapeutic studies; Philosophical and ethical issues related to stem cell research. This journal is indexed on CAS. The manuscript management system is completely online and includes a quick and fair peer-review system. Visit http://www.dovepress.com/ testimonials.php to read real quotes from published authors.. 